\title{
Growth inhibition by bio chemicals present in coffee extract on seedling growth in light and dark with reference to Vigna radiata (L.) Wilczek (mung bean). \\ Bhavana Gaur \\ Department of Botany R.G. (P.G.) College, Meerut-250001, Uttar Pradesh, India.
}

Received: May 15, 2016; Accepted: May 28, 2016.

\begin{abstract}
With a view to promote crop growth, seedling growth has been studied in vitro Biochemical effect of Coffee extract has been observed on seedling growth in Vigna radiata (L.) Wilczek Various concentrations of coffee extract (Coffea arabica) were tested on seedling growth of Vigna radiata (L.) Wilczek. Growth inhibition was observed.
\end{abstract}

Key words: Vigna radiata (L.) Wilczek; seedling growth Coffea arabica; coffee extract biochemical impact.

\section{Introduction}

Pulses are rich in proteins. Their food value is well known. They form an important part of Indian diet. With a view to promote crop growth, biochemical effect of extract of roasted coffee beans on seedlings of Vigna radiata (L.) Wilczek has been studied here.

Studies on the effect of plant extracts on seedling growth has been a point of investigation, since long. Some of them lay down the foundation of allelopathy. (Yardeni and Evenari, 1952): Earlier studies on effect of plant extracts on other plants were performed by Cannon etal (1962) and Carley and Watson (1968). Auti (2008) studied chemical effects. He studied effect of sodiumazide on peroxidase enzyme profile in Mung bean, Vigna radiata (L.) Wilczek Kumar and Kumar (2005), studied effect of Maleic Hydrazide on growth and flowering in Balsam (Impatiens balsamina L.) Chung etal (2001) identified allelopathic compounds from rice (oryza sativa $L$ ) straw and noted their biological activity.

Tea and coffee are common beverages. They form a common part of our day to day life. Coffee plant (Coffea arabica) is a member of family Rubiaceae. Roasted Coffee beans have been used here to form coffee extract. They contain caffetannic and which is known to be a mixture of chlorogenic acid and caffalic acid. According to Behl and Captain (1979), among the identified compounds of volatile oil present in roasted coffee beans are acetaldehyde, furan, furfurylaldehyde, forfuryl alcohol, pyridine, hydrogens sulphide etc. Coffee is inhaled by human beings as beverage and its effect on human system has been seen medicinally. Some of its deleterious effects have also been noticed. (Chopra et al. 1949).

How does coffee effect plant growth with the biochemicals present there in, such as chlorogenic acid? Such studies have not been taken earlier. Hence this work.

\section{Materials and Methods}

Commercial sample of Nescafe coffee sold in the market was taken. Roasted coffee beans present therein were, therefore, utilized. 10 grams of coffee powder was shaken with little amount of water to make paste, which was later made upto $1000 \mathrm{ml}$. This was filtered in Whatman No. 1 filter paper and constituted the standard or stock solution and represented weight/volume ratio of concentration 1:100. From this various other dilution were prepared e.g. weight/volume (W/V) $-1: 200 ; 1: 250 ; 1: 500$ and 1:1000 respectively. The investigated species along with their botanical names, common names, their families and their parts used in study are enlisted in Table 1.

Seeds of Vigna radiata (L.) Wilczek (Mung bean) were sterilized with $0.1 \%$ mercuric chloride solution along with petridishes to be used. They were then washed with distilled water. Five sets of aqueous extracts of different concentrations were taken with three replicates in each case along with water control. Seeds were kept on filter paper spread inside petriplate and smeared with aqueous extract or water so that the seeds could be wet.

Experiments were performed for 7 days. Light conditions used were - diffused day light and total darkness. Experiments were performed in laboratory conditions. Seedling growth was studied in relation to root length, shoot length, total seedling length and root/ shoot ratio respectively. In light, leaf length and breadth were also taken into consideration. Seedling growth was recorded on $4^{\text {th }}, 5^{\text {th }}, 6^{\text {th }}$ and $7^{\text {th }}$ day, respectively for various parameters taken are shown in Table 1.

\section{Corresponding Author}


Table 1: Name of plants investigated

\begin{tabular}{|c|c|c|c|c|}
\hline \multirow{2}{*}{ S.No. } & \multicolumn{3}{|c|}{ Name of Plant investigated/Plant part used for extract } & \multirow{2}{*}{ Family } \\
\hline & Botanical Name & Common Name & Plant used for Test & \\
\hline 1. & $\begin{array}{l}\text { Vigna radiata }(\mathrm{L} .) \text { Wilczek } \\
\text { (Plant investigated) }\end{array}$ & Mung (Green gram) & Fresh Seeds & $\begin{array}{l}\text { Leguminosae } \\
\text { (Fabaceae) } \\
\text { Sub-family Papilionatae }\end{array}$ \\
\hline 2. & $\begin{array}{l}\text { Coffea arabica } \\
\text { (Extract used) }\end{array}$ & Coffee & Seeds (Roasted) & Rubiace \\
\hline
\end{tabular}

Table 2: Effect of extracts of coffee beans in light on the seedling growth in Vigna radiata (L) Wilczek.

\begin{tabular}{|c|c|c|c|c|c|c|c|}
\hline \multirow{2}{*}{ S.No. } & \multirow{2}{*}{ Variable } & \multirow{2}{*}{$\begin{array}{c}\text { Days after } \\
\text { sowing }\end{array}$} & \multirow{2}{*}{ Control } & \multicolumn{4}{|c|}{ Coffee beans extracts Concentrations (W/V) } \\
\hline & & & & $1: 200$ & $1: 250$ & $1: 500$ & 1:1000 \\
\hline \multirow{4}{*}{1.} & & 4 & $16 \pm 3.4$ & $3.83 \pm 1.31$ & $2.83 \pm 1.34$ & $1.80 \pm 1.20$ & $2.00 \pm 0.00$ \\
\hline & Root length & 5 & $16.50 \pm 3.14$ & $3.33 \pm 1.55$ & $3.33 \pm 1.25$ & $2.16 \pm 1.31$ & $2.50 \pm 0.00$ \\
\hline & \pm S.D. $(\mathrm{cms})$ & 6 & $17.13 \pm 3.21$ & $4.00 \pm 1.41$ & $3.66 \pm 1.44$ & $2.66 \pm 1.31$ & $3.0 \pm 0.00$ \\
\hline & & 7 & $17.88 \pm 3.11$ & $5.50 \pm 1.08$ & $4.33 \pm 1.25$ & $3.33 \pm 1.25$ & $4.33 \pm 0.47$ \\
\hline \multirow{4}{*}{2.} & & 4 & $2.83 \pm 0.94$ & $6.00 \pm 041$ & $7.23 \pm 1.41$ & $8.00 \pm 1.35$ & $7.16 \pm 1.31$ \\
\hline & Shoot length & 5 & $2.88 \pm 1.14$ & $6.50 \pm 4.01$ & $8.16 \pm 1.31$ & $8.50 \pm 1.35$ & $7.66 \pm 1.31$ \\
\hline & \pm S.D. $(\mathrm{cms})$ & 6 & $3.50 \pm 1.27$ & $7.33 \pm 0.47$ & $9.00 \pm 1.41$ & $9.00 \pm 1.35$ & $8.33 \pm 1.25$ \\
\hline & & 7 & $4.25 \pm 1.52$ & $8.50 \pm 1.41$ & $9.66 \pm 1.31$ & $9.66 \pm 1.25$ & $9.16 \pm 1.31$ \\
\hline
\end{tabular}

Table 3: Effect of extracts of coffee beans in light on the total length, root/shoot ratio and leaf dimensions in Vigna radiata (L) Wilczek.

\begin{tabular}{|c|c|c|c|c|c|c|c|}
\hline \multirow{2}{*}{ S.No. } & \multirow{2}{*}{ Variable } & \multirow{2}{*}{$\begin{array}{c}\text { Days after } \\
\text { sowing }\end{array}$} & \multirow{2}{*}{ Control } & \multicolumn{4}{|c|}{ Coffee beans extracts Concentrations (W/V) } \\
\hline & & & & $1: 200$ & $1: 250$ & $1: 500$ & 1:1000 \\
\hline \multirow{4}{*}{1.} & \multirow{4}{*}{ Total length (cms) } & 4 & 18.83 & 9.83 & 10.06 & 9.80 & 9.16 \\
\hline & & 5 & 19.38 & 9.83 & 11.49 & 10.66 & 10.16 \\
\hline & & 6 & 20.63 & 11.33 & 12.66 & 11.66 & 11.33 \\
\hline & & 7 & 22.13 & 14.00 & 13.99 & 12.99 & 13.49 \\
\hline \multirow{4}{*}{2.} & \multirow{4}{*}{ Root/Shoot Ratio (length) } & 4 & 1:0.18 & $1: 1.57$ & $1: 2.55$ & $1: 4.44$ & $1: 3.58$ \\
\hline & & 5 & 1:0.17 & $1: 1.95$ & $1: 2.45$ & $1: 3.94$ & $1: 3.06$ \\
\hline & & 6 & $1: 0.20$ & $1: 1.83$ & $1: 2.46$ & $1: 3.38$ & $1: 2.78$ \\
\hline & & 7 & $1: 0.24$ & $1: 1.55$ & $1: 2.23$ & $1: 2.90$ & $1: 2.12$ \\
\hline 3. & Leaf Length (mm) & 7 & 14.50 & 14.20 & 13.00 & 14.00 & 10.00 \\
\hline 4. & Leaf Breadth (mm) & 7 & 5.00 & 5.70 & 6.80 & 6.20 & 5.20 \\
\hline
\end{tabular}

Table 4: Effect of Extracts of Coffee beans in dark on the seedling growth in Vigna radiata (L) Wilczek.

\begin{tabular}{|c|c|c|c|c|c|c|c|}
\hline \multirow{2}{*}{ S.No. } & \multirow{2}{*}{ Variable } & \multirow{2}{*}{$\begin{array}{c}\text { Days after } \\
\text { sowing }\end{array}$} & \multirow{2}{*}{ Control } & \multicolumn{4}{|c|}{ Coffee beans extracts Concentrations (W/V) } \\
\hline & & & & 1:200 & $1: 250$ & $1: 500$ & 1:1000 \\
\hline \multirow{4}{*}{1.} & \multirow{4}{*}{$\begin{array}{l}\text { Root length } \\
\pm \text { S.D. }(\mathrm{cms})\end{array}$} & 4 & $7.66 \pm 1.70$ & $4.50 \pm 1.80$ & $3.00 \pm 0.41$ & $4.66 \pm 1.60$ & $4.50 \pm 0.41$ \\
\hline & & 5 & $8.50 \pm 1.81$ & $5.33 \pm 0.94$ & $3.66 \pm 0.47$ & $6.00 \pm 1.78$ & $5.33 \pm 0.47$ \\
\hline & & 6 & $9.00 \pm 1.87$ & $5.83 \pm 0.94$ & $4.33 \pm 0.62$ & $6.50 \pm 1.78$ & $6.00 \pm 0.71$ \\
\hline & & 7 & $9.66 \pm 1.70$ & $6.33 \pm 0.94$ & $5.00 \pm 0.82$ & $6.66 \pm 2.00$ & $7.33 \pm 0.47$ \\
\hline \multirow{4}{*}{2.} & \multirow{4}{*}{$\begin{array}{l}\text { Shoot length } \\
\pm \text { S.D. }(\mathrm{cms})\end{array}$} & 4 & $21.66 \pm 2.36$ & $16.00 \pm 1.63$ & $13.33 \pm 1.70$ & $13.66 \pm 3.36$ & $17.66 \pm 2.05$ \\
\hline & & 5 & $23.33 \pm 1.89$ & $17.33 \pm 2.05$ & $14.66 \pm 2.45$ & $18.00 \pm 0.82$ & $19.33 \pm 2.49$ \\
\hline & & 6 & $24.66 \pm 2.36$ & $19.33 \pm 2.05$ & $16.00 \pm 2.27$ & $19.16 \pm 0.85$ & $21.00 \pm 3.24$ \\
\hline & & 7 & $25.66 \pm 2.36$ & $20.66 \pm 2.49$ & $17.00 \pm 2.16$ & $20.33 \pm 0.57$ & $22.66 \pm 3.30$ \\
\hline
\end{tabular}

Table 5: Effect of Extracts of Coffee beans in dark on total length and root / shoot ratio in Vigna radiata (L) Wilczek.

\begin{tabular}{|c|c|c|c|c|c|c|c|}
\hline \multirow{3}{*}{ S.No. } & \multirow{3}{*}{ Variable } & \multirow{3}{*}{ Days after sowing } & \multirow{3}{*}{ Control } & \multirow{2}{*}{\multicolumn{4}{|c|}{$\begin{array}{l}\text { Coffee beans extracts } \\
\text { Concentrations }(\mathrm{W} / \mathrm{V})\end{array}$}} \\
\hline & & & & & & & \\
\hline & & & & $1: 200$ & $1: 250$ & $1: 500$ & $1: 1000$ \\
\hline \multirow{4}{*}{1.} & \multirow{4}{*}{ Total length (cms) } & 4 & 29.32 & 20.50 & 16.33 & 18.32 & 22.16 \\
\hline & & 5 & 31.83 & 22.66 & 18.32 & 24.00 & 24.66 \\
\hline & & 6 & 33.66 & 25.16 & 20.33 & 25.66 & 27.00 \\
\hline & & 7 & 35.52 & 26.99 & 22.00 & 26.99 & 29.99 \\
\hline \multirow{4}{*}{2.} & \multirow{4}{*}{ Root/Shoot Ratio (length) } & 4 & $1: 2.83$ & $1: 3.50$ & $1: 4.44$ & $1: 2.93$ & $1: 3.92$ \\
\hline & & 5 & $1: 2.74$ & $1: 3.25$ & $1: 4.01$ & $1: 3.00$ & $1: 3.63$ \\
\hline & & 6 & $1: 2.74$ & $1: 3.32$ & $1: 3.76$ & $1: 2.95$ & $1: 3.50$ \\
\hline & & 7 & $1: 2.66$ & $1: 3.26$ & $1: 3.40$ & $1: 3.05$ & $1: 3.09$ \\
\hline
\end{tabular}


Plate 1: Seedling Growth

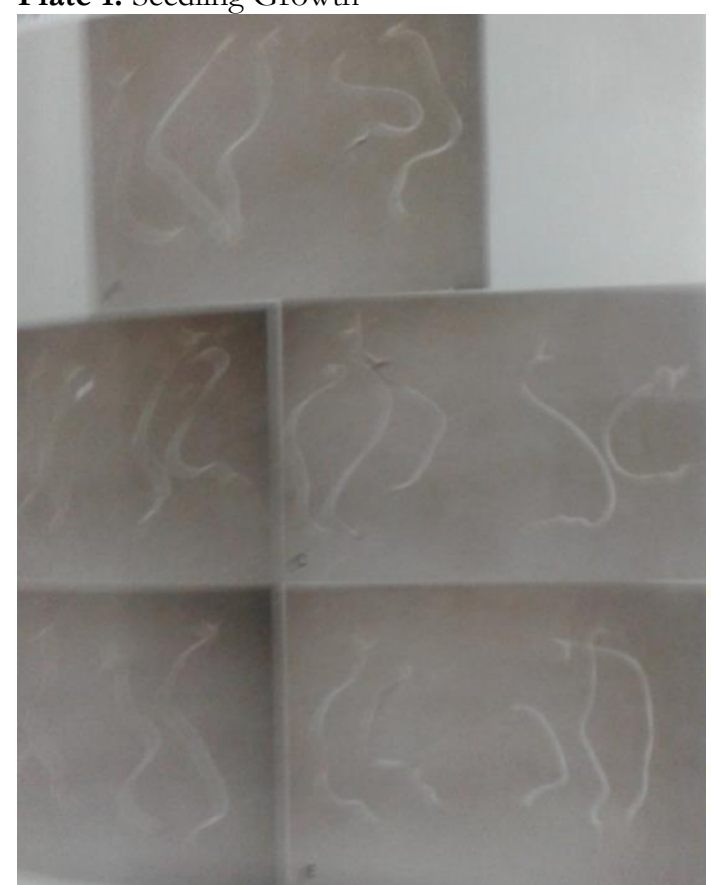

7 days old seedling of Vigna radiate (L) Wilczek in coffee extract concentrations and control in light.

Fig. A: Effect of control; Fig. B: Effect of concentration W/V - 1:200; Fig. C: Effect of concentration W/V - 1:250; Fig. D: Effect of concentration $\mathrm{W} / \mathrm{V}-1: 500$; Fig. E: Effect of concentration $\mathrm{W} / \mathrm{V}-1: 1000$.

Plate 2: Seedling Growth

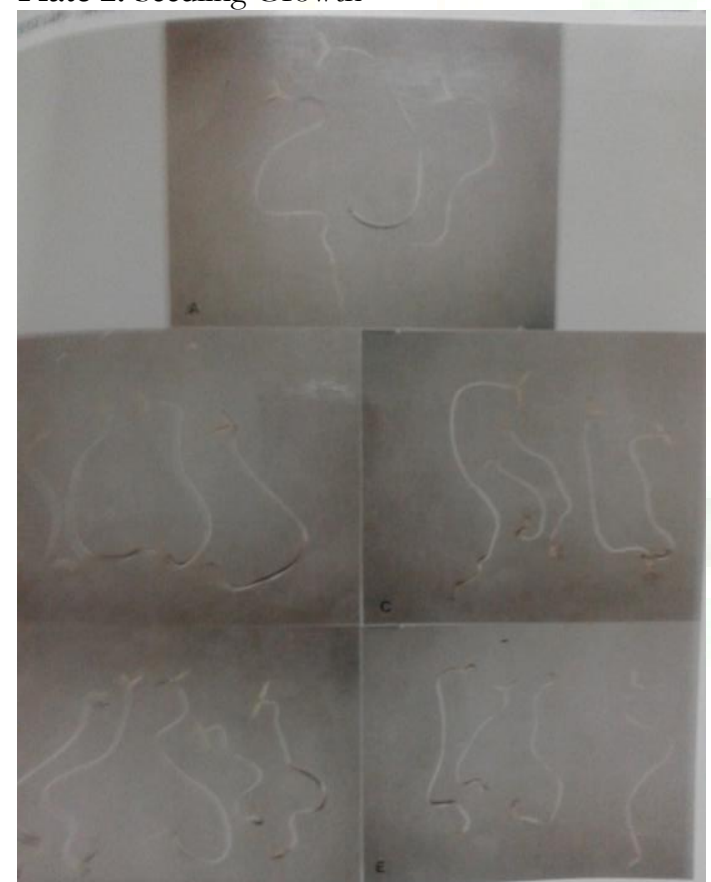

7 days old seedling of Vigna radiate (L) Wilczek in coffee extract concentrations and control in dark. Fig. A Effect of control; Fig. B Effect of concentration W/V-1:200; Fig. C Effect of concentration W/V-1:250; Fig. D Effect of concentration W/V-1:500; Fig. E Effect of concentration W/V $-1: 1000$.

\section{Results and Discussion}

Nutrition is important for all the organisms, plants, animals and human beings. Pulses form an important part of diet. For improvement of Vigna radiata $(\mathrm{L})$ Wilczek, study is undertaken to see the biochemical effect of coffee extract prepared from seeds of Coffea arabica.

The effect of alternating periods of light and darkness on tissues of Phaseolus vulgaris cultivar has been studied by Al-Subai and Horwath, I (1981). Effect of biochemicals inherent in plant extracts has also been studied by many investigators. Gurudev and Saxena (1991) have made observations on seed treatments with bioregulators in relation to wheat productivity. Auti etal (2008) prepared peroxidase isozyme profile in Mung bean i.e. Vigna radiata (L.) Wilczek as affected by sodium azide. Kumar and Kumar (2005) studied the effect of Maleic Hydrazide on growth and flowering in Balsam (Impatiens balsamine L.)

Coffee extract promotes shoot length in light at all concentrations in Vigna radiata (L) Wilczek. In darkness neither root length nor shoot length is promoted in coffee extract. It is inhibited at all the given concentrations of coffee extract. Maximum inhibition in root and shoot were found at concentration $(\mathrm{W} / \mathrm{V})-1: 250$. Leaf length decreased in coffee extract in light. Leaf breadth was promoted slightly in coffee extract in light. Maximum inhibition was observed in dilution $(\mathrm{W} / \mathrm{V})-1: 1000$ in leaf length. Maximum promotion on leaf breadth was found at concentration (W/V) $-1: 250$.

Coffee, generally taken as beverage has some harmful effects. Dermatitis has been reported in workers engaged in roasting coffee beans. The volatile aromatic constituents produce local irritation and reflex stimulation (Chopra etal 1949). Chlorogenic acid is allergenic under certain conditions. Urticaria dermatitis (Kaye and Freedman, 1961) and allergic rhinitis etc. is found in persons employed in serving out or roasting coffee beans. Patch tests were positive to chaffe in $69 \%$ of the affected persons.

Ume Moto (1971) studied that chlorogenic acid influences flower production in long day duckweed Lemna gibba. Allelo pathic interactions of Populous deltoides leaf lechates with some crop plants has been studied by Ahlawat Kumar A and Vimla Y. (2008). Babu and Kumar (1979) studied seed germination and early seedling growth of Cicer arietinum Linn. CV-235, Cajanus cajan, sprang CV Pusa Agati, Phaseolus aureus Ham CV-58 and Phaseolus mungo Linn. CV P-1 undergrowth regulators and salinity stressed conditions.

Recently Gaur and Gaur (2010a) studied biochemical impact of Endogenous Hormones inherent in Eucalyptus leaves on senescence in Vigna mungo (L) Hepper for its use as biofertilizer. 
Gaur and Gaur (2010b) again studied the effect of Eucalyptus leaf extract on senescence in primary leaves of Phaseolus lunatus and its genetic control. They studied the properties of Eucalyptus leaves as biofertilizer.

Singhal and Sharma (1981) studied changes in biochemical composition of soil organic matter consequent upon growing Eucalyptus in Sal zone of Doon Valley, India.

Growth inhibition and germination inhibition has been studied by Yardeni and Evenari (1952) and phytocidal effects of certain leaves and leaf extracts have been observed. Such inhibitory effect has been observed in present experiment and inhibitory effect of coffee extract has been found on seedling growth of Vigna radiata (L) Wilcret. However, coffee extract promotes shoot length in light at dilute concentration, optimum concentration being W/V 1:1000. It promotes leaf breadth in light also. Inhibition in total seedling length is found in coffee extract in Vigna radiata (L.) Wilczek both in light and dark. These results are in accordance with the earlier work done on allelopathy.

\section{Acknowledgement}

It is my faithful endeavor at this moment to thank Dr. R. Shiam, Ex-Head, Department of Botany, Meerut College, Meerut. I feel a deep sense of gratitude for the guidance provided by him.

\section{References}

1. Ahlawat Kumar A and Y. Vimla, 2008, Allelopathic interaction of Populous deltoides leaf lechates with some crop plants. JIBS $\underline{87}, 3$ \& 4): 145-146.

2. AL-Subai, M.Y. \& I. Horwath, 1981, The effect of alternating period of light and darkness on tissues of Phaseolus vulgaris cultivar. Acta Univ. Szged. Act Biol. 26: 41-50.

3. Auti, S.G., S.C. Dalave and B.J. Apparao, 2008, Effect of Sodium azide on peroxidase isozyme profile in Mung bean, Vigna radiata, L) Wilczek) J. India Bot. Soc. 87,1 \& 2): 145-146.

4. Babu, V.R. and Kumar, S., 1979, Seed germination and early seedling growth of Cicer arientinum Linn. CV.235, cajacus caijan sprang CV Pusa Agati, Phaseolus aureus Ham. CV - 58 and Phaseolus mungo Linn. CV P-I undergrowth regulators and salinity stressed conditions. J.I.B.S. 58: 140-148.

5. Behl, P.N. and R.M. Captain, 1979, Skin Irritant and Sensitizing plants found in India. Ed. 2, iii, xxi, 55. S. Chand and Co. Ltd., Ramnagar, New Delhi.

6. Cannon, J.R., W.H. Corbett, K.P. Haydock, J.G. Tracey, J.G. and L.J. Webbo, 1962, An investigation of the effect of the dehydro argustriae present in leaf litter of Beck bausia angustifolia on the germination of Aurocaria cunninghamia - an experimental approach to the problem of rain forest ecolos: Aust J.Bo. 10: 119 128

7. Carley, H. and RD Watson, 1968, Effect of various plant extracts upon seed germination. Bot. Gaz. 129(1): 57-62.

8. Chopra R.N., R.L, Bahadur, and G.S. Ghosh, 1949, Poisonous plant of India. The Indian Council of Agricultural Research, Delhi.

9. Chung I.M., J.K. Ann. And S.J. Yun, 2001, Identificatioin of allelopathic comlpounds from Rice, Oryza Sativa L) straw and their biological activity. Can. J.P. Sel. Sci. 81, 1) 815-819.

10. Gaur, Bhavana and Varada Gaur, 2010a, "Biochemical Impact of Endogenous Hormones inherent in Eucalyptus leaves on Senescence in Vigna mungo, L) Hepper for its use as biofertilizer." Journal of Plant Development Science, 2, 1\& 2): pp 35-39.

11. Gaur, Bhavana and Varada Gaur, 2010b): "Senescence in Primary Leaves of Phaseolus lunatus, its genetic control, as affected by Eucalyptus leaf extract and properiety of later as biofertilizer". In Voyoger 1: pp 95-103.

12. Gurudev S and O.P. Saxena, 1991, Seed treatments with bioregulators in relation to wheat productivity in: "New Trends in plant Physiology", Proceedings National Symposium on "Growth and Differentiation in Plants", New Delhi, India) p.p. 201-210.

13. Kaye, M. and S.O. Freedman, 1961, An allergy to coffee - An occupational disease. Canad., Med. Ass. J. 84: 460 .

14. Kumar, J. and S. Kumar, 2005, Effect of Maleic Hydrazide on growth and flowering in Balsam, Impatiens balsamina L) J. Of Orn. Hort. 7(1): 129-30.

15. Singhal, R.M. and S.D. Sharma, 1981, Changes in biochemical composition of soil organic matter consequent upon growing Eucalyptus in Sal Zone of Doon Valley, India. Indian J. For., 4): 48-49.

16. Umemoto, T., 1971, Effect of chlorogenic acid on flower production in long day duck weed, Lemna gibba. Plant Cell Physiol. 12: 165 - 169

17. Yardeni, D. and M. Evenari, 1952, The germination inhibiting, growth inhibiting and Phytocidal effect of certain leaves and leaf extracts. Phyton Buenos Aires. 2: $11-16$.

\section{Cite this article as:}

Bhavana Gaur. Growth inhibition by bio chemicals present in coffee extract on seedling growth in light and dark with reference to Vigna radiata (1) wilczek (mung bean). Annals of Plant Sciences 5.5 (2016): 1344-1347.

Source of support: Nil

Conflict of interest: None Declared 